\title{
Material Response and Failure Mechanism of Unidirectional Metal Matrix Composites under Impulsive Shear Loading
}

\author{
L.H. Dai ${ }^{1}$, Y.L. Bai ${ }^{1}$ and S-W.R. Lee ${ }^{2}$ \\ ${ }^{1}$ LNM, Institute of Mechanics, Chinese Academy of Sciences, Beijing 100080, P.R. China \\ ${ }^{2}$ Department of ME, Hong Kong University of Science \& Technology, Kowloon, Hong Kong \\ Keywords: Metal Matrix Composites, High Strain Rate, Shear Strength, Shear Failure Mechanism
}

\begin{abstract}
The material response and failure mechanism of unidirectional metal matrix composite under impulsive shear loading are investigated in this paper. Both experimental and analytical studies were performed. The shear strength of unidirectional $C_{f} / A 356.0$ composite and $A 356.0$ aluminum alloy at high strain rate were measured with a modified split Hopkinson torsional bar technique. The results indicated that the carbon fibers did not improve the shear strength of aluminum matrix if the fiber orientation aligned with the shear loading axis. The microscopic inspection of the fractured surface showed a multi-scale zigzag feature which implied a complicated shear failure mechanism in the composite. In addition to testing, the micromechanical stress field in the composite was analyzed by the generalized Eshelby equivalent method (GEEM). The influence of cracking in matrix on the micromechanical stress field was investigated as well. The results showed that the stress distribution in the composite is quite nonhomogeneous and very high shear stress concentrations are found in some regions in the matrix. The high shear stress concentration in the matrix induces tensile cracking at $45^{\circ}$ to the shear direction. This in turn aggravates the stress concentration at the fiber/matrix interface and finally leads to a catastrophic failure in the composite. From the correlation between the analysis and experimental results, the shear failure mechanism of unidirectional $C_{f} / A 356.0$ composite can be elucidated qualitatively.
\end{abstract}

\section{INTRODUCTION}

Shear strength and failure mechanism is one of the most significant problems for fiber reinforced composites. With increasing applications and development of fiber reinforced metal matrix composites (FRMMC) in aerospace, high speed train, and automobile industries, the understanding of the shear behaviour of FRMMC becomes more and more important. In the past decade, there have been several attempts to study the dynamic shear response and fracture behaviour of fiber reinforced polymer matrix composites (FRPMC) by split Hopkinson bar technique with a variety of shear loading and specimen geometry. Among them, the use of the split Hopkinson torsional bar (SHTB) for the study of the dynamic shear behaviour of FRPMC seems to be the most straightforward approach. The first two attempts to use SHTB were made by Parry \& Harding [1] and Chiem \& Liu [2], in which the short thin-walled and cuboid specimens were adopted, respectively. A very significant increase in shear strength with strain rates was observed for both woven and cross-ply glass/epoxy composite specimens. More recently, SHTB was also used by Leber \& Lifshitz [3] to examine the shear response of plain-wave fiber reinforced laminates, in which thin-walled tubular specimens with a large aspect ratio were used. Their results showed that the material exhibits high sensitivity to loading rates. 
There have also been attempts to use the split Hopkinson pressure bar (SHPB) for the study of shear strength of FRPMC. In 1986, Werner \& Dharan [4] performed a test based upon the shortbeam shear of SHPB to investigate the interlaminar and the transverse shear strength of a plain-wave carbon/epoxy laminates. The results showed no significant effect of strain rate. Bouette et al. [5] used a double-notched specimen of unidirectional carbon/epoxy composite. They also conducted a finite element stress analysis and found large shear stress concentrations at the notch area. Besides, Harding et al. $[6,7]$ suggested a double-lap and a single-lap shear specimen consecutively to determine the interlaminar shear strength of composite laminates. Although a great progress has been made in the investigation of the dynamic shear strength of FRPMC at high strain rates, only very little attention has been paid to the systematic analysis of the shear failure mechanism so far $[8,9]$. Furthermore, almost all studies were focused on the dynamic shear strength of FRPMC, while the dynamic shear strength and failure mechanism FRMMC at high strain rates were rarely explored.

It is well known that the macroscopic failure of materials usually results from the evolution of internal microdamage. The nucleation, extension and coalescence of microdamage are related to the internal micromechanical stress state. Therefore, the micromechanical stress field in the unidirectional fiber composite subjected to longitudinal shear loading must be analyzed in order to reveal the shear failure mechanism. In the past, problems related to unidirectional fiber reinforced composites under longitudinal shear have been studied by a number of investigators. Tsai [10] and Adams et al. $[11,12]$ treated a doubly periodic rectangular array fiber composite with linear elasticity and finite difference technique. In their analysis, the local stress distribution in the matrix was obtained. However, they did not provide the stress distribution in the fibers. Goree \& Wilson [13], Budiansky \& Carrier [14] and Steif [15] studied the problem of two cylinders or holes embedded in infinite linear elastic body. By means of the complex variable theory, the average stress distribution in the matrix between two cylinders or holes was obtained. However, their results can not be applied to the actual fiber reinforced composites, which contain large amounts of cylindrical fibers. Accordingly, a further complete investigation of the micromechanical stress field, including the stress state in both fibers and matrix in unidirectional fiber composites under longitudinal shearing is still necessary.

Unidirectional fiber reinforced composite is a nonhomogeneous multi-phase material in microscopic sense. The micromechanical stress analysis of the material is usually confronted with great difficulty compared with the case of monolithic materials. However, the generalized Eshelby equivalent inclusion method (GEEM), based upon the Eshelby equivalent inclusion scheme [16] and the Mori-Tanaka average stress concept [17], is a promising approach to analyze the micromechanical stress field in nonhomogeneous multi-phase medium [18-25]. If a fiber is considered to be a cylindrical inclusion, the fiber composite can then be regarded as a body containing many cylindrical inclusions. Therefore, GEEM can be used to deal with the unidirectional fiber composites subjected to longitudinal shear loading.

The present work is an attempt to address the shear failure mechanism of unidirectional carbon/aluminum composite. Both experimental and analytical studies were performed. The shear strength of unidirectional $C_{p} / A 356.0$ composite and $A 356.0$ aluminum alloy at high strain rate were measured with a modified split Hopkinson torsional bar (SHTB) technique. The results indicated that the carbon fibers did not improve the shear strength of aluminum matrix if the fiber orientation aligned with the shear loading axis. The microscopic inspection of the fractured surface by a scanning electronic microscope (SEM) showed a multi-scale zigzag feature which implied a complicated shear failure mechanism in the composite. In addition, the micromechanical stress field in the unidirectional $C_{f} / A 356.0$ composite under longitudinal shear loading is analyzed in order to interpret the experimental results. However, only static linear elastic stress analysis is performed although the composite presents elastoplastic shear behaviour. There are reasons for doing this. One is due to the great difficulty in dynamic elastoplastic stress analysis for nonhomogeneous medium. 
The other is due to the fact that the unidirectional $C_{f} / A 356.0$ composite reveals little strain rate effect on its shear response and behaves elastically until shear failure occurs. With the use of GEEM, a micromechanical stress field in the unidirectional $C_{f} / A 356.0$ composite is obtained. The analytical results show that the stress distribution in the composite is quite nonhomogeneous and very high stress concentration can be found in local regions in the matrix for a certain fiber volume fraction. After combining the micromechanical stress analysis and the experimental results, the damage initiation and failure mechanism of the unidirectional $\mathrm{C}_{\mathrm{f}} / \mathrm{A} 356.0$ composite can be elucidated.

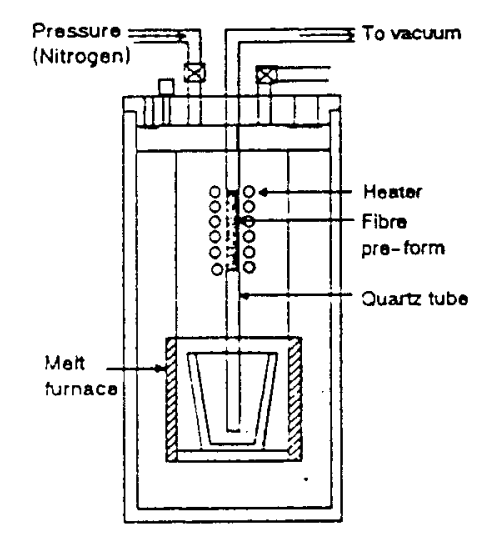

Fig. 1 Pressure Infiltration Casting Set-up

\section{EXPERIMENTAL INVESTIGATION}

\subsection{Specimen Preparation}

The unidirectional $C_{f} / A 356.0$ composite and $A 356.0$ aluminum alloy were fabricated by pressure infiltration casting under the same condition. This method allows inexpensive development and production of composite materials, and has found wide applications. The set-up used in the present study is shown in Fig. 1. A block of A356.0 aluminum was placed in a crucible and the pre-form of the unidirectional carbon fibers was placed on the top of the block. The crucible was loaded into a furnace inside a pressure chamber and heated in vacuum. When the metal melted, it flowed around the pre-form, but isolated the vacuum in the pre-form. Then the vessel was pressurized, forcing the liquid metal to flow into the fiber pre-form. At last, the set-up was cooled down to a designed temperature and the casting sample was completed. In our study, the casting sample was a circular bar with $22 \mathrm{~mm}$ in diameter. In the sample, the carbon fibers were aligned along the longitudinal direction of the bar. The fiber volume fraction was $50 \%$. The microstructure of the unidirectional C f A 356.0 composite is shown in Fig. 2. The nominal properties of the fiber and matrix alloy are listed in Table 1.

Table 1 Nominal Properties of Fiber and Matrix of $\mathrm{C}_{\mathrm{f}} / \mathrm{A} 356.0$ Composite

\begin{tabular}{|c|c|c|c|c|}
\hline & \multicolumn{2}{|l|}{ Fiber } & \multicolumn{2}{|c|}{ Matrix } \\
\hline Type & $T-300$ & & A35 & $.0 \mathrm{Al}(7.0 \mathrm{Si}-0.35 \mathrm{Mg}-0.1 \mathrm{Ti})$ \\
\hline Diameter & 7 & $\mu \mathrm{m}$ & & \\
\hline Tensile Strength & 3500 & $\mathrm{MPa}$ & 182 & $\mathrm{MPa}$ \\
\hline Tensile Modulus & 235 & $\mathrm{GPa}$ & 80 & GPa \\
\hline Density & 1.76 & $\mathrm{~g} / \mathrm{cm}^{3}$ & 2.72 & $\mathrm{~g} / \mathrm{cm}^{3}$ \\
\hline
\end{tabular}



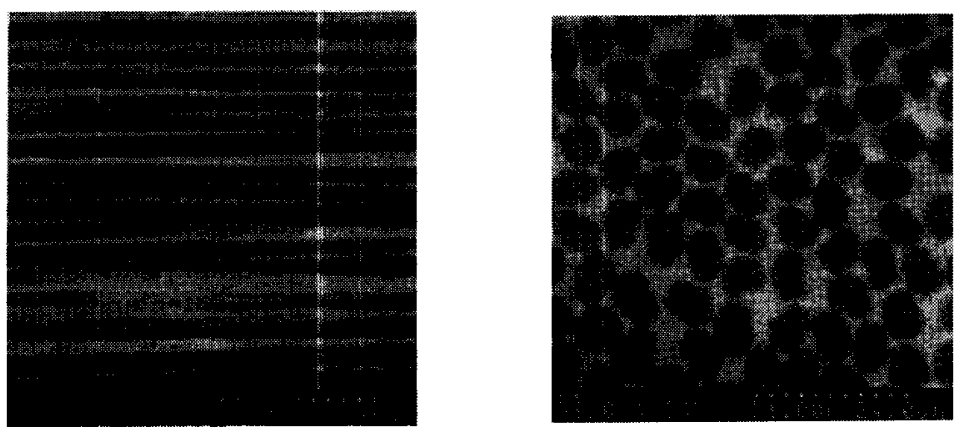

Fig. 2 SEM Micrographs of $\mathrm{C}_{\mathrm{A}} / \mathrm{A} 356.0$ Composite

Both $C_{d} / A 356.0$ composite and A356.0 aluminum alloy in the present investigation are short thinwalled tubular specimen. The gauge length and thickness of specimen range within 1.9 2.1 mm and $0.5 \sim 0.7 \mathrm{~mm}$, respectively. The fibers were oriented aligned in the direction of the torsional axis. The picture of specimen is shown in Fig. 3.

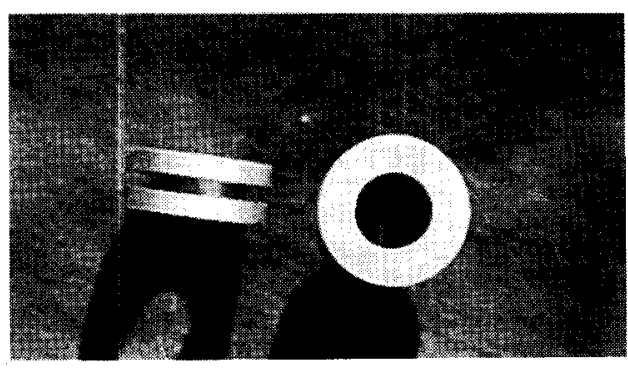

Fig. 3 Short Tubular Specimen for SHTB Testing

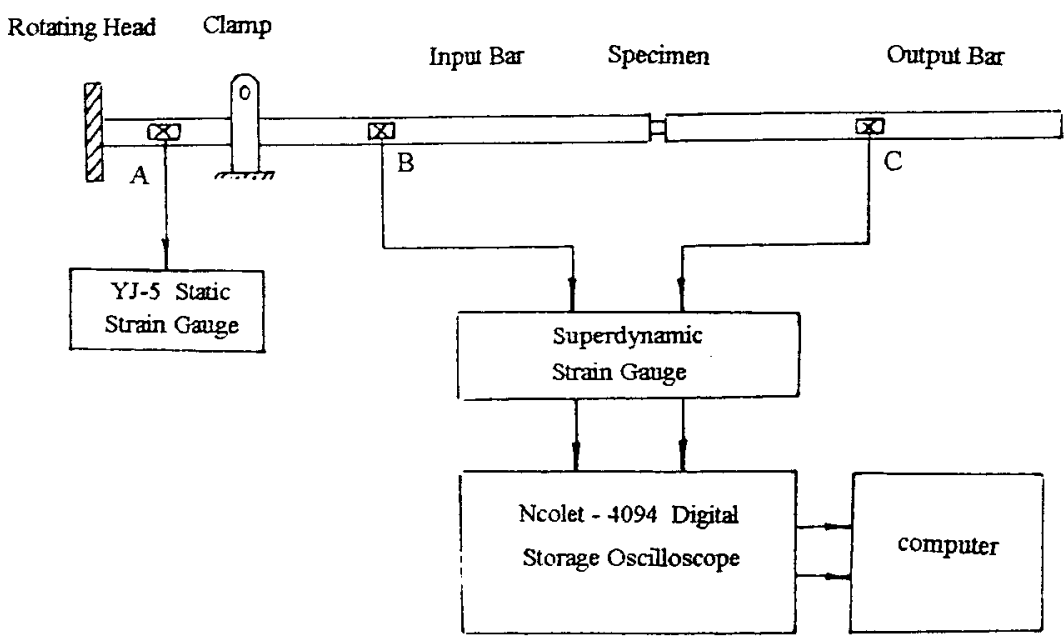

Fig. 4 Schematic Diagram of SHTB Testing System 


\subsection{SHTB Testing Procedures}

The schematic diagram of split Hopkinson torsional bar (SHTB) apparatus used in the present experiments is shown in Fig. 4. Since the SHTB has many advantages over other apparatus, it is widely used to characterize the shear behaviour of materials at high strain rates. In the present experimental study, the short thin-walled tubular specimen was sandwiched between the input and output bars with $25 \mathrm{~mm}$ in diameter. The bars are supported by a series of U-blocks which allow the bars to rotate freely. Before testing, the torque provided by a hydraulic pump was stored in a portion of the input bar between the clamp and the rotating head. The stored torque was monitored by strain gauges attached to the bars. As the clamp was abruptly released, a torsional pulse propagated through the input bar and loaded the specimen. Simultaneously, part of the pulse reflected back to the input bar and the counter part was transmitted into the output bar. According to the elastic properties of the bars and the recording pulse signals, the shear stress transmitted through the specimen can be determined.

The incident, reflected and transmitted pulses were measured by two sets of $90^{\circ}$ rosette strain gauges mounted diametrically opposite each other on the input and output bars. The signals from the input and output bars were fed through a dynamic strain amplifier to a digital oscilloscope. Therefore, the shear stress, shear strain rate and shear strain can be calculated according to the recordings of the incident torque wave $M_{i}$ and the reflected torque $M_{r}$ recorded by the gauges on the input bar and the transmitted torque wave $M_{t}$ recorded by the gauges on the output bar [26]:

$$
\begin{gathered}
\tau=\frac{M_{t}(t)}{2 \pi r_{s}^{2} \delta} \\
\dot{\gamma}=\frac{2 r_{s} C_{0}}{1_{s} J_{b} G_{b}}\left(M_{i}(t)-M_{t}(t)\right) \\
\gamma=\frac{2 r_{s} C_{0}}{1_{s} J_{b} G_{b}} \int_{0}^{t}\left(M_{i}(t)-M_{t}(t)\right) d t
\end{gathered}
$$

where $1_{s}, r_{s}, \delta$ are the gauge length, mean radius, and thickness of the specimen, and $C_{0}, J_{b}, G_{b}$ are the elastic wave speed, the polar moment of inertia, and shear modulus of the bars, respectively.

Table 2 Dynamic Shear Strength

\begin{tabular}{ccc}
\hline Materials & $\bar{\tau}_{\mathrm{b}}$ (MPa) & Quantity of Specimen \\
\hline A356.0 & $321 \pm 3$ & 5 \\
C $_{\mathrm{f}} / \mathrm{A} 356.0$ & $329 \pm 7$ & 5 \\
\hline
\end{tabular}

\subsection{Results and Discussion}

A series of torsional impact tests $\left(\dot{\gamma}=10^{2} \sim 10^{3} 1 / \mathrm{s}\right)$ were conducted with the SHTB for both unidirectional $C_{f} / A 356.0$ composite and A356.0 aluminum alloy. Figs. 5 and 6 present typical oscilloscope records from the tests on the composite and the matrix, respectively. The top trace gives the incident and reflected strain pulses, while the bottom trace gives the transmitted strain pulse. The average dynamic shear strength for the composite and the matrix are given in Table 2. The typical shear stress strain curves for both the composite and the matrix are shown in Figs. 7 and 8 , respectively. The results demonstrate that the dynamic shear strength of the unidirectional $C_{\mathrm{f}} / \mathrm{A} 356.0$ composite is almost the same as that of the matrix. This indicates that the current carbon fiber orientation which aligns with the torsional loading axis does not improve the shear strength of the matrix effectively. 


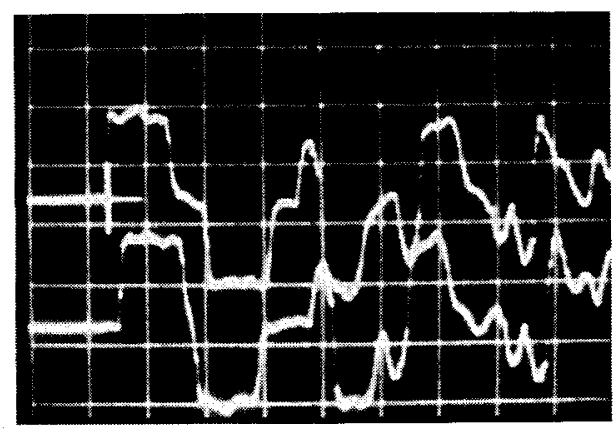

Fig. 5 SHTB Signal of A356.0 Alloy

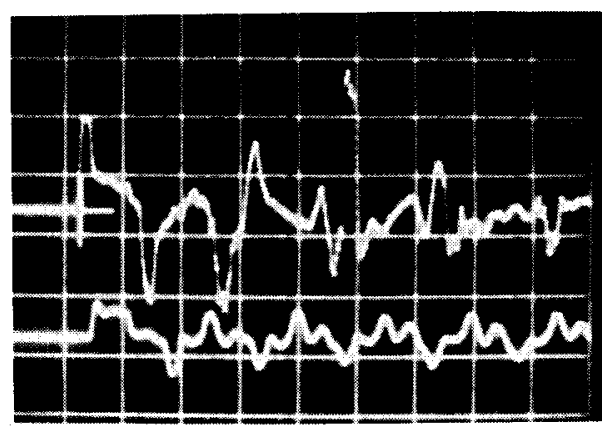

Fig. 6 SHTB Signal of $C_{d} / A 356.0$ Composite

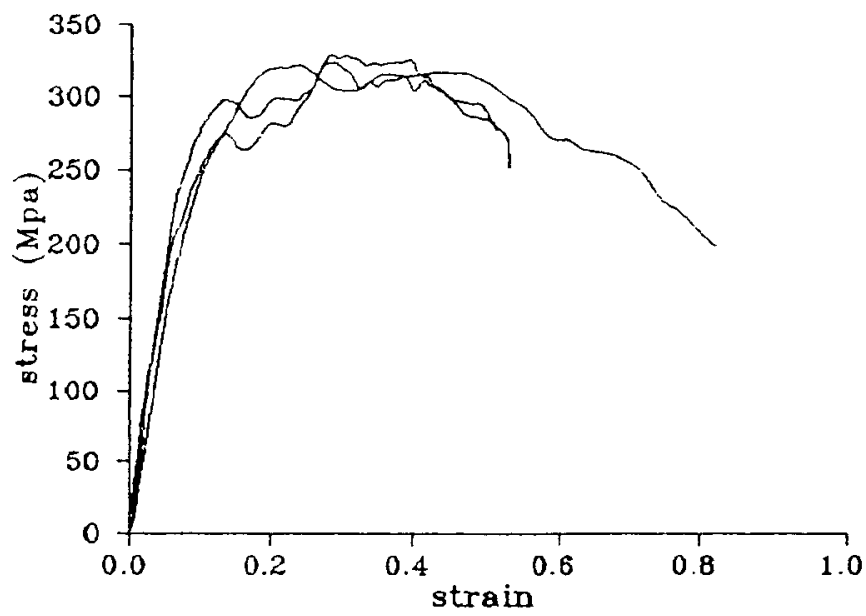

Fig. 7 Dynamic Shear Stress-Strain Relation of A356.0 Alloy

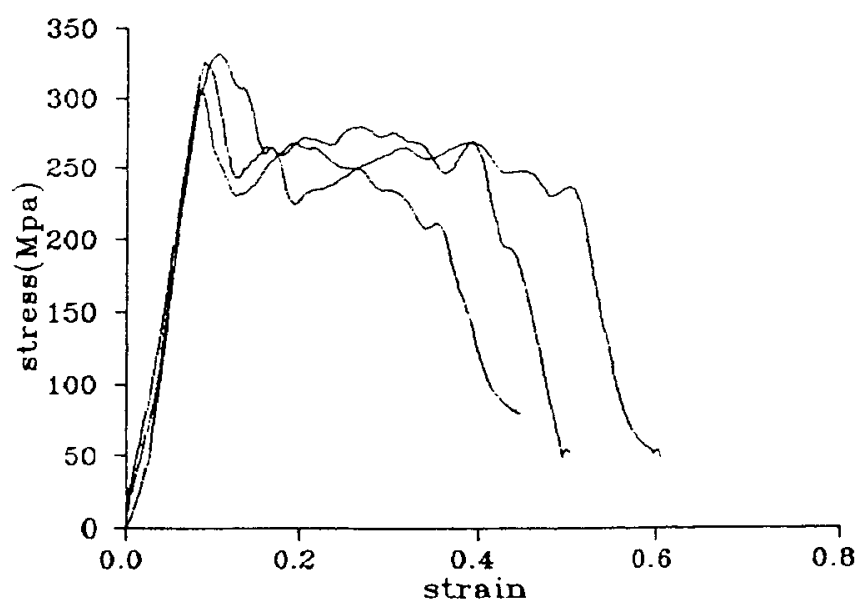

Fig. 8 Dynamic Shear Stress-Strain Relation of $C_{f} / A 356.0$ Composite 


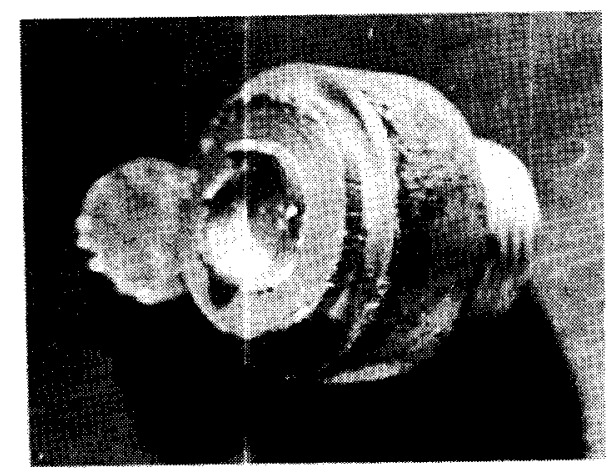

Fig. 9 The Cf/A356.0 Composite Specimen Failed by SHTB Testing
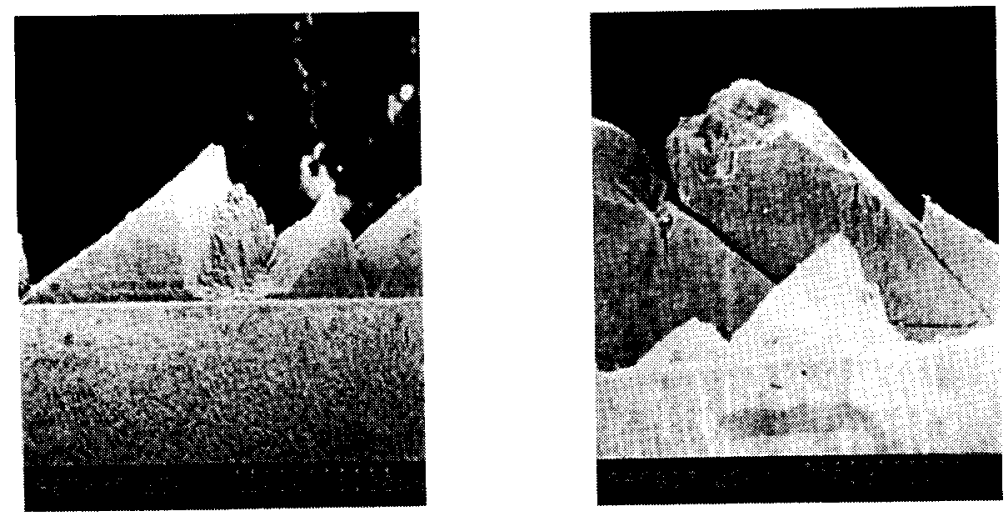

Fig. 10 Micrographs of the Zigzags on the Fractured Surface of $C_{d} / A 356.0$ Composite
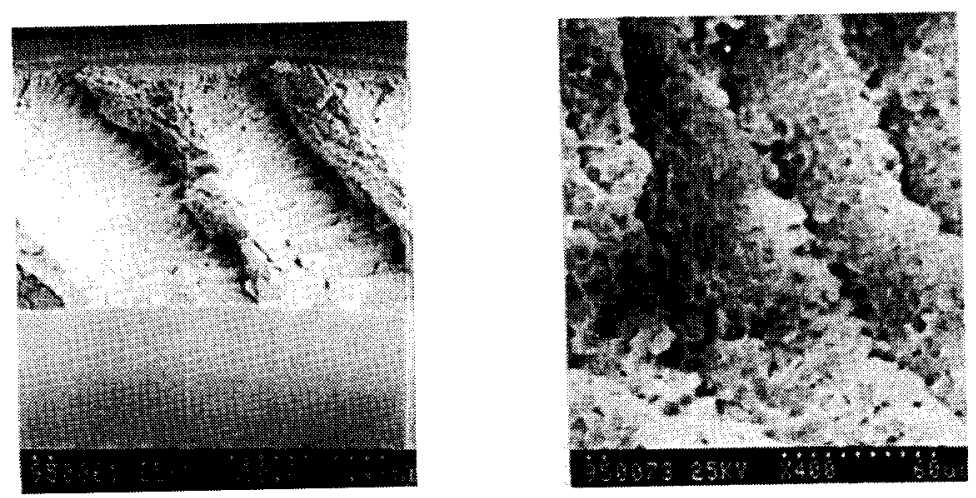

Fig. 11 Multi-scale Zigzag Feature of $C_{d} / A 356.0$ Composite Specimen 
From the shear stress strain curves shown in Figs. 7 and 8, one can find that the shear behaviour of the matrix is quite different from that of the composite. The composite shows a rather brittle failure response other than the pure matrix alloy. Note that the failure strain for the composite and the pure matrix alloy is 0.1 and 0.5 , respectively. Furthermore, the shear failure of composite experiences a multi-stage process (Fig. 8). When the shear strain reaches about 0.1 , the load-bearing capacity of the composite falls from the peak ( $>330 \mathrm{MPa})$ to a plateau ( $260 \mathrm{MPa})$. Subsequently, the composite maintains this stress until the catastrophic failure occurs. It is obvious that this complicated failure process is due to the interaction between fibers and the matrix in the composite. Moreover, the failure surfaces of the unidirectional $C_{f} / A 356.0$ composite observed by a scanning electronic microscope (SEM) show an interesting multi-scale zigzag feature as shown in Figs. 9-11. This may be due to the tensile failure at $45^{\circ}$ to the shear direction. But the failure surfaces of the matrix have no such feature. Therefore, this is a unique feature of shear failure in the unidirectional $\mathrm{C}_{\mathrm{f}} / \mathrm{A} 356.0$ composite.

The multi-stage failure process and the multi-scale zigzag failure surface of the unidirectional $\mathrm{C}_{\mathrm{f}} / \mathrm{A} 356.0$ composite imply a complicated shear failure mechanism. It is well known that the macroscopic failure of the materials usually results from the evolution of the nucleation, extension and coalescence of microdamage. Each of these micromechanical processes is determined by its corresponding stress state. In order to understand the shear failure mechanism of the FRMMC, a micro-mechanics approach must be adopted to analyze the stress field and the damage evolution.
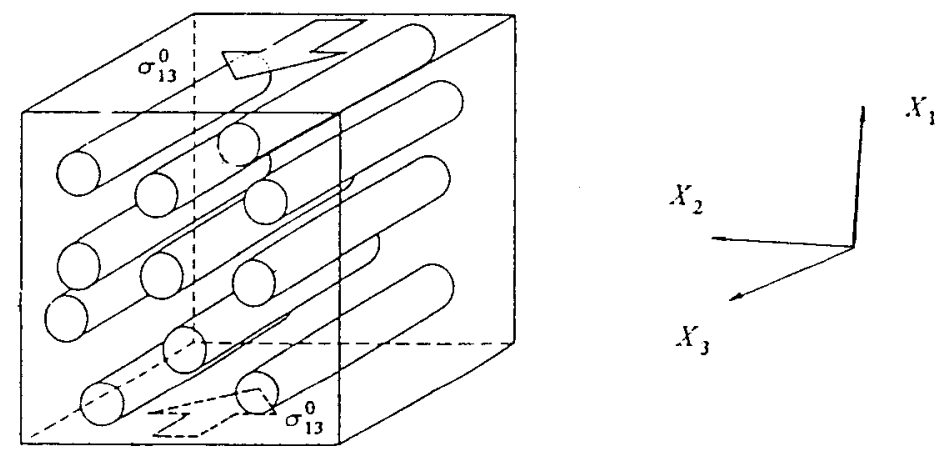

Fig. 12 Schematic Diagram for the Longitudinal Shearing of Unidirectional Composite
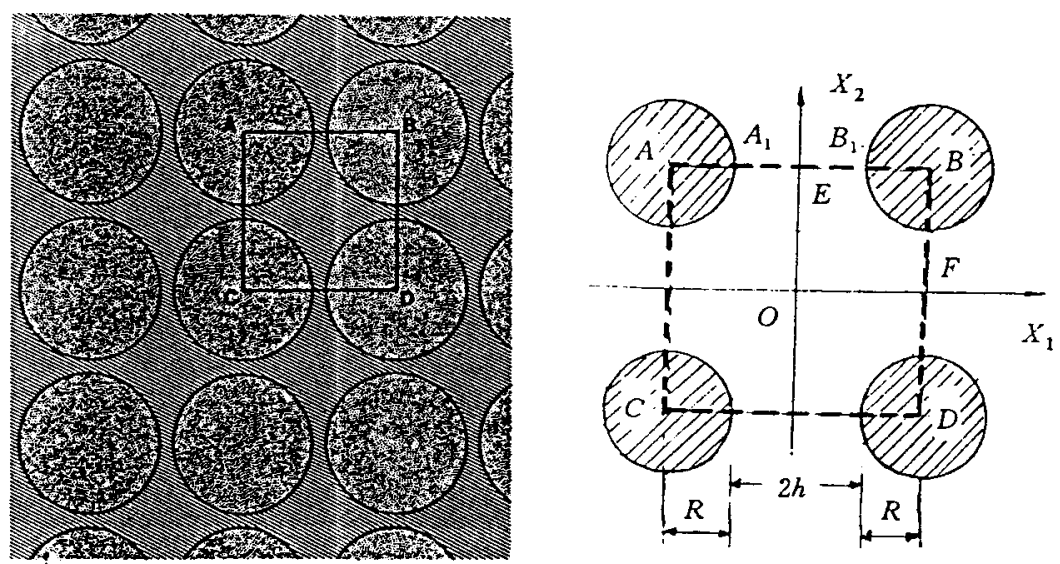

Fig. 13 Unit Cell for the Micro-Mechanics Stress Analysis 


\section{MICROMECHANICAL STRESS FIELD}

In this section, micromechanical stress field in the unidirectional $\mathrm{C}_{\mathrm{f}} / \mathrm{A} 356.0$ composite under longitudinal shear is analyzed with the generalized Eshelby equivalent inclusion method (GEEM). The basic principle of GEEM is described briefly hereby. The detailed formulation can be found in the literature [16-23].

Consider an infinite composite body which contains infinite number of fiber inclusions aligned along $X_{3}$ axis. Assume both fiber and matrix phase are homogeneous, isotropic and linear elastic. The elastic stiffness of the matrix and fibers are $C_{i j k l}^{m}$ and $C_{i j k l}^{f}$, respectively. A traction force $\sigma_{i j}^{0} n_{j}$ is prescribed on the boundary of the body. The force will produce a uniform stress $\sigma_{i j}^{0}$ and strain $\varepsilon_{i j}^{0}$, when the body does not contain any fiber inclusions, that is

$$
\sigma_{\mathrm{ij}}^{0}=\mathbf{C}_{\mathrm{ijk}}^{\mathrm{m}} \varepsilon_{\mathrm{kl}}^{0}
$$

According to the GEEM and EIAS [22], the following equations can be deduced:

$$
\begin{gathered}
\mathrm{C}_{\mathrm{ijkl}}^{\mathrm{f}}\left(\varepsilon_{\mathrm{kl}}^{0}+\bar{\varepsilon}_{\mathrm{kl}}+\mathrm{S}_{\mathrm{klmn}} \varepsilon_{\mathrm{mn}}^{*}\right)=\mathrm{C}_{\mathrm{ijkl}}^{\mathrm{m}}\left(\varepsilon_{\mathrm{kl}}^{0}+\bar{\varepsilon}_{\mathrm{kl}}+\mathrm{S}_{\mathrm{klmn}} \varepsilon_{\mathrm{mn}}^{*}-\varepsilon_{\mathrm{kl}}^{*}\right) \\
\mathrm{C}_{\mathrm{ijkl}}^{\mathrm{m}} \bar{\varepsilon}_{\mathrm{kl}}+\mathrm{V}_{\mathrm{f}} \mathrm{C}_{\mathrm{ijkl}}^{\mathrm{m}}\left(\mathrm{S}_{\mathrm{klmn}} \varepsilon_{\mathrm{mn}}^{*}-\varepsilon_{\mathrm{kl}}^{*}\right)=0
\end{gathered}
$$

where $\bar{\varepsilon}_{\mathrm{ij}}$ is the average strain disturbance due to all fiber inclusions in the matrix, $\varepsilon_{\mathrm{ij}}^{*}$ is the fiber equivalent eigenstrain, $V_{f}$ is the fiber volume fraction and $S_{i j k l}$ is the Eshelby tensor of the fiber inclusions. The explicit expressions of $S_{i j k l}$ for an infinite cylindrical fiber inclusion were given by Mura [18].

If a longitudinal shear problem is considered as shown in Fig. 12, only $\sigma_{13}^{0}$ does not equal zero among the external applied stress components. According to Moschovidis \& Mura [25], the assumption of the constant eigenstrain $\varepsilon_{\mathrm{ij}}^{*}$ is enough to get accurate result for the multi-inclusion problem if a constant external loading is applied. Hence, from Eqs. (5) and (6), we obtain

$$
\begin{aligned}
& \varepsilon_{13}^{*}=2 B \varepsilon_{13}^{0} \\
& \bar{\varepsilon}_{13}=V_{f} B \varepsilon_{13}^{0}
\end{aligned}
$$

where $B=(1-K) /\left[2 K+\left(1-V_{f}\right)(1-K)\right]$ and $K=G_{f} / G_{m}, G_{f}$ and $G_{m}$ are the shear stiffness of the fiber and the matrix, respectively. Once $\bar{\varepsilon}_{\mathrm{ij}}$ and $\varepsilon_{\mathrm{ij}}^{*}$ are determined, the stress in the fibers $\sigma_{\mathrm{ij}}^{\mathrm{f}}$ and the stress at an arbitrary point in the matrix $\sigma_{\mathrm{ij}}^{\mathrm{m}}(\mathrm{X})$ can be calculated by the following expressions, respectively:

$$
\begin{gathered}
\sigma_{\mathrm{ij}}^{\mathrm{f}}=\mathrm{C}_{\mathrm{ijkl}}^{\mathrm{f}}\left(\varepsilon_{\mathrm{kl}}^{0}+\bar{\varepsilon}_{\mathrm{kl}}+\mathrm{S}_{\mathrm{klmn}} \varepsilon_{\mathrm{mn}}^{*}\right)=\mathrm{C}_{\mathrm{ijkl}}^{\mathrm{m}}\left(\varepsilon_{\mathrm{kl}}^{0}+\bar{\varepsilon}_{\mathrm{kl}}+\mathrm{S}_{\mathrm{klmn}} \varepsilon_{\mathrm{mn}}^{*}-\varepsilon_{\mathrm{kl}}^{*}\right) \\
\sigma_{\mathrm{ij}}^{\mathrm{m}}(\mathrm{X})=\mathrm{C}_{\mathrm{ijkl}}^{\mathrm{m}}\left(\varepsilon_{\mathrm{kl}}^{0}+\sum_{\mathrm{l}}^{\mathrm{N}} D_{\mathrm{klm} n}^{\mathrm{q}}(\mathrm{X}) \varepsilon_{\mathrm{mn}}^{*}\right)
\end{gathered}
$$

where $N$ is the number of the fibers considered in the concrete calculation and $D_{k l m}(X)$ is the generalized Eshelby tensor of the fiber inclusion. Note that the implicit expression of $D_{\text {klmn }}(X)$ was given by Mura [18], but the explicit ones were not shown. It is quite difficult to derive a general expression of $D_{k \mathfrak{m}}(X)$ especially for infinite cylindrical fiber inclusion. However, through an 
ingenious variable transformation, all explicit forms of $D_{k l m n}(X)$ can easily be obtained. For the purpose of the present study, only those related to the longitudinal shear problem are given:

$$
\begin{aligned}
& D_{1313}(X)=\frac{1}{4 \pi}\left(\frac{\pi R^{2}}{X_{1}^{2}+X_{2}^{2}}-\frac{2 \pi R^{2} X_{1}^{2}}{\left(X_{1}^{2}+X_{2}^{2}\right)^{2}}\right) \\
& D_{2323}(X)=\frac{1}{4 \pi}\left(\frac{\pi R^{2}}{X_{1}^{2}+X_{2}^{2}}-\frac{2 \pi R^{2} X_{2}^{2}}{\left(X_{1}^{2}+X_{2}^{2}\right)^{2}}\right)
\end{aligned}
$$

where $\mathbf{R}$ is the radius of fiber. In the following calculation, the fibers were assumed to be distributed uniformly in the matrix as shown in Fig. 13. This allows us to focus our attention on the region of $\mathrm{ABCD}$ in the composite. In order to verify the accuracy of the present calculation, comparisons between the present GEEM's solutions and Adams's finite difference solutions [11] as well as Goree's two-cylindrical inclusions [13] are given in Table 3. It is noticeable that Goree's solution is only suitable for the case of very low fiber volume fraction $\left(V_{f}\right)$. This comparison demonstrates that the present solutions are quite satisfactory.

Table 3 Comparison of Matrix Stress Concentration Factor (SCF)

\begin{tabular}{cllll}
\hline $\mathrm{V}_{\mathrm{f}}(\%)$ & $\mathrm{G}_{\mathrm{f}} / \mathrm{G}_{\mathrm{m}}$ & GEEM & Adams & Goree \\
\hline \multirow{4}{*}{4} & 2 & 1.329 & - & - \\
& 6 & 1.696 & 1.849 & 1.734 \\
& 20 & 1.875 & 2.110 & 1.432 \\
& 120 & 1.948 & 2.222 & 2.014 \\
\hline \multirow{4}{*}{40} & 2 & 1.342 & - & - \\
& 6 & 1.645 & 1.684 & 2.154 \\
& 20 & 1.772 & 1.906 & 2.551 \\
& 120 & 1.820 & 2.006 & 2.729 \\
\hline \multirow{4}{*}{55} & 2 & 1.372 & - & - \\
& 6 & 1.677 & 1.831 & 2.558 \\
& 20 & 1.797 & 2.174 & 3.200 \\
& 120 & 1.842 & 2.339 & 3.505 \\
\hline
\end{tabular}

For unidirectional $C_{f} / A 356.0$ composite $\left(G_{f} / G_{m} \cong 3, v=0.20, V_{f}=50 \%\right)$, the three-dimensional stress concentration factor ( $\mathrm{SCF}=\sigma_{13} / \sigma_{13}^{0}$ ) distributions in the region of OFBE (see Fig. 13) are shown in Fig. 14. From Fig. 14, one can find that the stress distributions are nonhomogeneous. There is a uniform stress concentration in the fiber owing to the constant equivalent eigenstrain $\varepsilon_{\mathrm{ij}}^{*}$. Furthermore, the nonhomogeneous stress distributions in the matrix are greatly affected by the fiber volume fraction $V_{f}$. When $V_{f}$ reaches $50 \%$ which corresponds to the realistic fiber volume fraction of the unidirectional $C_{f} / A 356.0$ composite, the shear stress concentration in the region (surrounding $\mathrm{EB}_{1}$ in Fig. 13) near the "interface" (defined as a thin matrix region close to the fiber's surface) is much higher than that in both the fiber and the other regions in the matrix.

In order to reveal this high shear stress concentration more clearly, SCF distributions along line $A A_{1} E B_{1} B$ (in Fig. 13) are given in Figs. 15 and 16. The effects of $V_{f}$ and $G_{f} / G_{m}$ on SCF in fibers and matrix are also presented. The results indicate that SCF in $A_{1} \mathrm{~EB}_{1} B$ are much higher than that in fibers if $V_{f}$ exceeds a critical value, $31 \%$. It is obviously that the high SCF shall initiate microdamage in the matrix. This will be analyzed in details in the next section. 

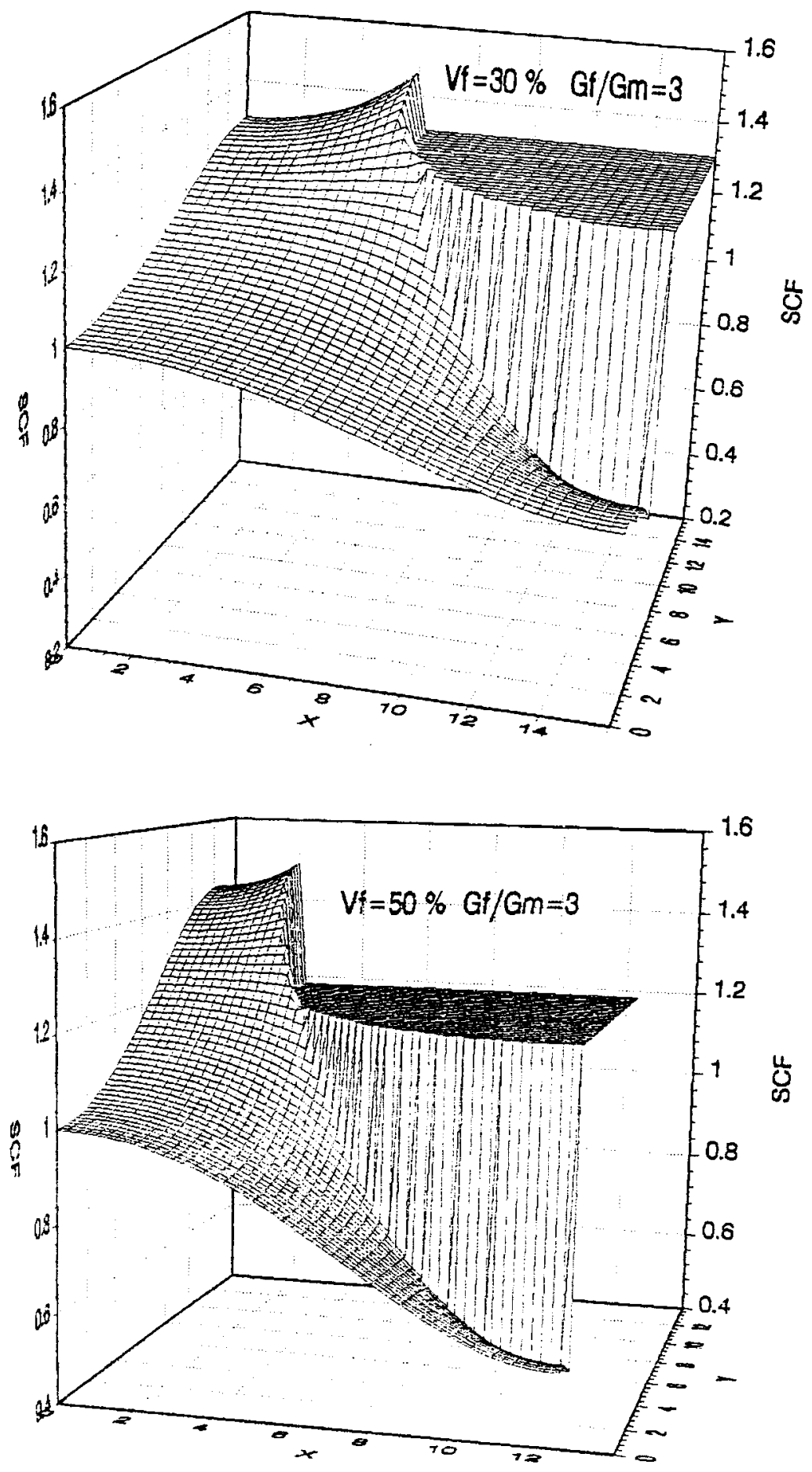

Fig. 14 3-D Shear Stress Concentration Factor (SCF) Distribution in OFBE 

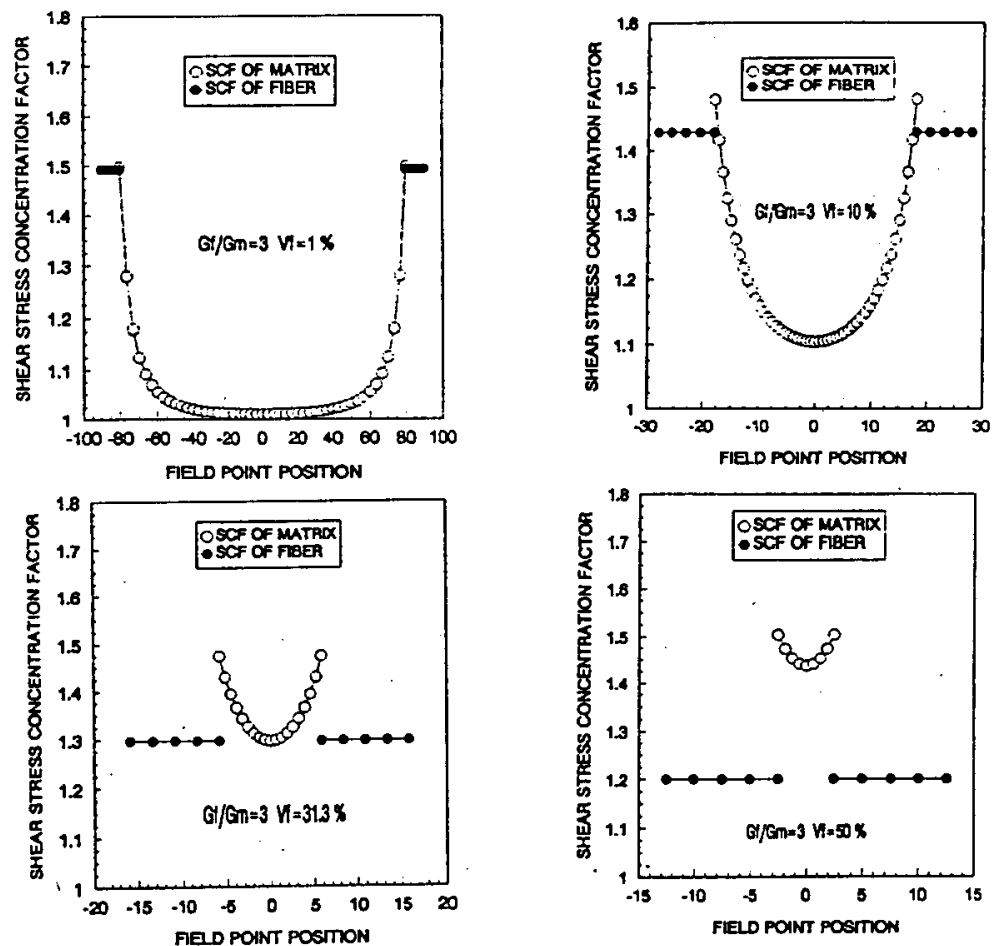

Fig. 15 SCF Distribution along a Line of $A_{1} \mathrm{~EB}_{1} B$
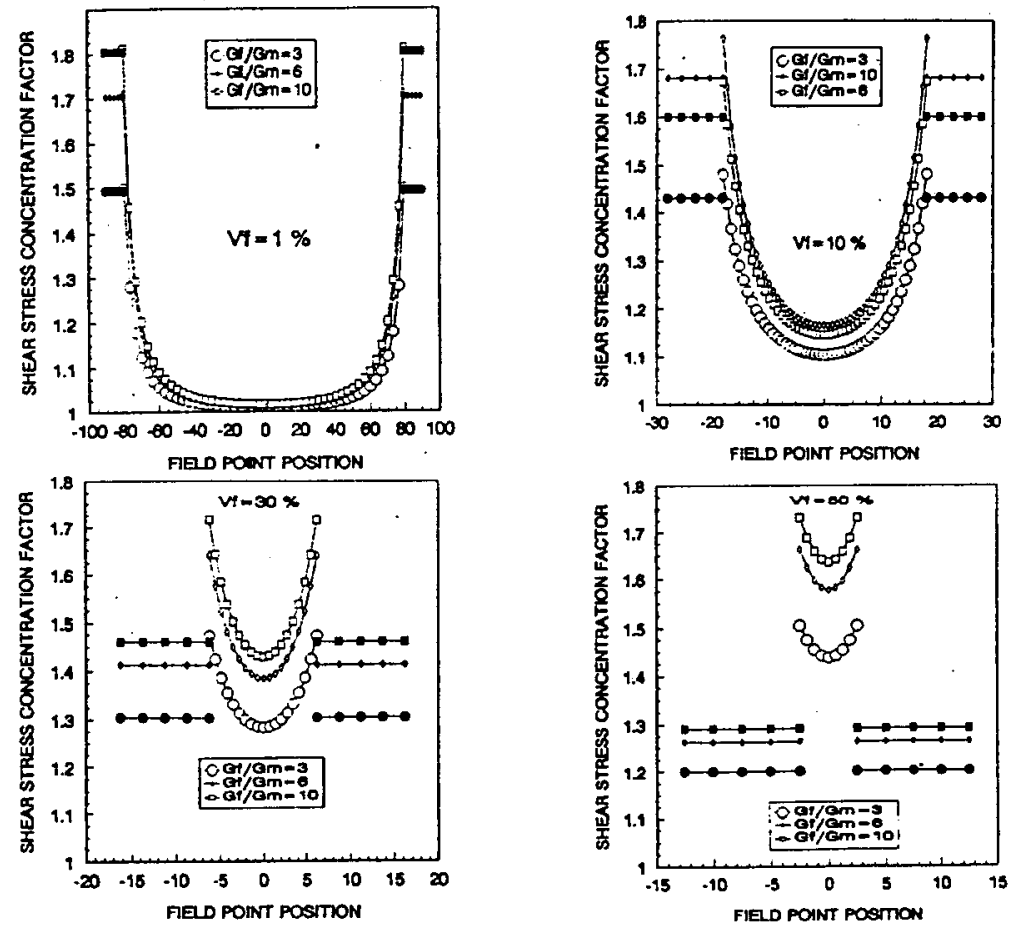

Fig. 16 Influence of $V_{f}$ and $G_{f}^{\prime} G_{m}$ on SCF along a Line of $A A_{1} E B_{1} B$ 


\section{SHEAR FAILURE PROCESS AND MECHANISMS}

\subsection{Damage Initiation-Shear Induced Matrix Tensile Crack}

As many other fiber reinforced composites, the unidirectional $\mathrm{C}_{\mathrm{f}} / \mathrm{A} 356.0$ may experience many kinds of microdamage modes, such as matrix cracking, interface debonding and fiber fracture etc., when subjected to longitudinal shear loading. However, which one is initiated precedently should be determined in the light of the internal stress state and the mechanical properties of the constituents.

From Table 1, the carbon fiber has very high strength $\left(\sigma_{b}=3500 \mathrm{MPa}\right)$, hence fibers are difficult to fracture during the early stage of deformation. However, the analytical results in the last section show that there exist very high SCF in both the local matrix region and the interface, particularly when the SCF in the interface is much higher than in the matrix. Therefore, if the two regions have the equal strength, damages will be initiated at the interface first. But, according to the tensile tests and the analytical results, the shear strength of the interface of the unidirectional $C_{f} / A 356.0$ composite is not lower than $211 \mathrm{MPa}$. Hence, the interface shear failure does not seem to be prone to occur at the early stage of deformation.
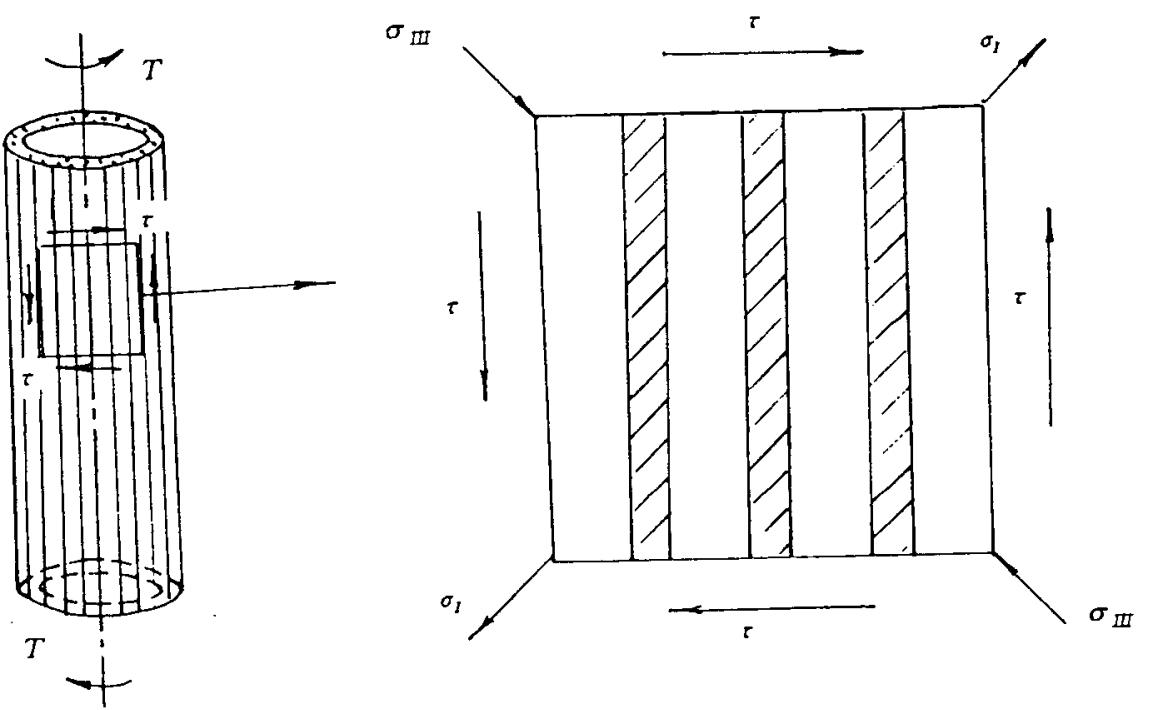

Fig. 17 Schematic Diagram of Loading and Equivalent Stress State of Torsional Shearing

Fig. 17 is a schematic diagram of shear and the corresponding equivalent stress state of the unidirectional $C_{A} / A 356.0$ composite subjected to torsional loading. The shear stress $(\tau)$ is equivalent to a tensile stress $\left(\sigma_{\mathrm{I}}\right)$ at $45^{\circ}$ to the shear direction together with a compression ( $\sigma_{\mathrm{III}}$ ), with $\sigma_{1}=-\sigma_{\mathrm{II}}=\tau$ in the matrix. According to the experimental investigation, for the matrix (A356.0 cast aluminum alloy), the tensile strength is not higher than the shear one. Therefore, when the composite is subjected to a longitudinal shear loading, instead of shear failure, the regions with high SCF in the matrix may crack first due to the principal tensile stress $\sigma_{I}$ at $45^{\circ}$ to the shear direction. Following Piggott [8], we call this failure mode as shear induced tensile crack (SITC). The crack condition can be expressed as:

$$
\sigma_{13}^{0} K_{13}^{m}(X)=\sigma_{b}^{m} \quad \text { or } \quad \sigma_{I}^{m}(X)=\sigma_{b}^{m}
$$


where $K_{13}^{m}(X)=\sigma_{13}^{m}(X) / \sigma_{13}^{0}, \sigma_{13}^{0}$ is the applied shear stress, $\sigma_{I}^{m}(X)$ is the principal tensile stress at a point $X$ in the matrix and $\sigma_{b}^{m}$ is tensile strength of the matrix.

In order to further verify the aforementioned SITC phenomenon in the matrix further, some Iospescu in-situ shear tests of the A356.0 cast aluminum alloy were conducted by a Hitachi-S-570 scanning electronic microscope (SEM) which is equipped with a loading stage. The failure process is illustrated in Fig. 18. One can find that many tensile cracks at $45^{\circ}$ to the shear direction are initiated in the shear zone between the two notches before the macroscopic shear failure occurs. In practice, the torsional shear failure surfaces of the unidirectional $C_{f} / A 356.0$ composite also show many matrix cracks as shown in Fig. 19. Accordingly, the initiation of microdamage can be determined as SITC in the matrix.

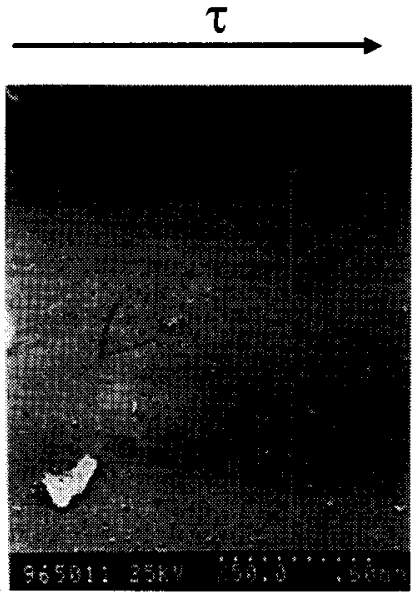

$\tau$

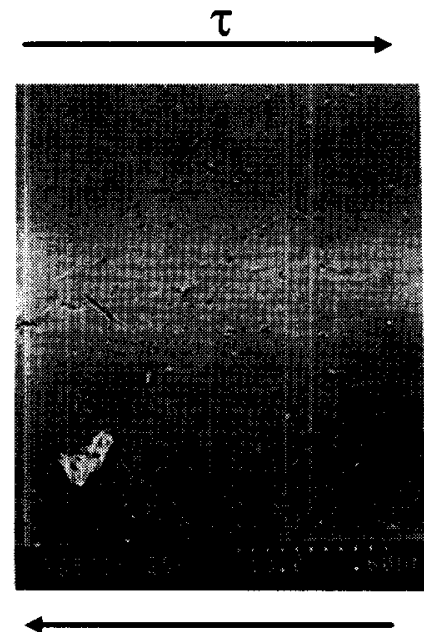

$\tau$

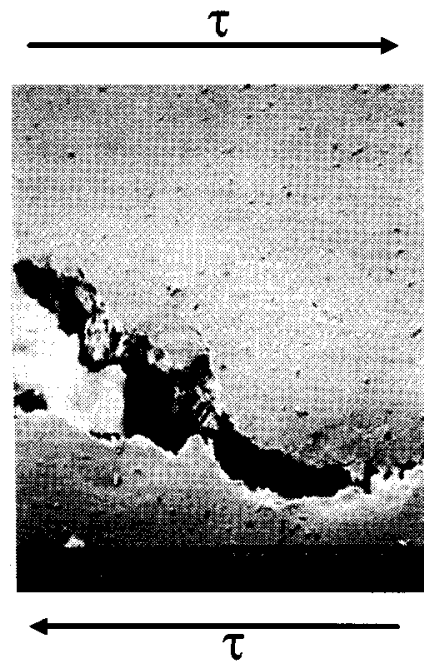

Fig. 18 Progressive Failure of A356.0 Aluminum Alloy Subjected to Iosipescu Shear Test
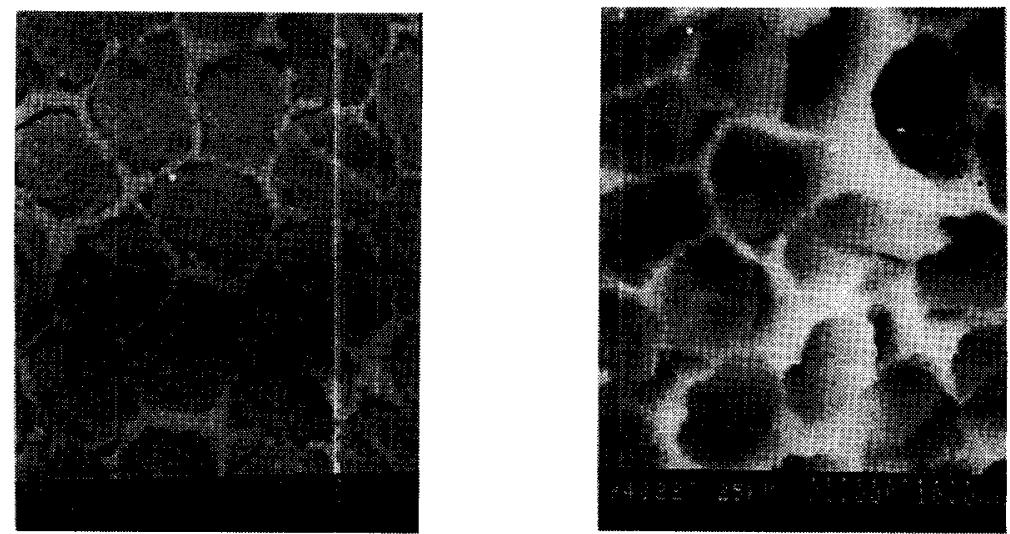

Fig. 19 Torsional Shear Failure Surface of Unidirectional $C_{f} / A 356.0$ Composite 


\subsection{Effects of the Matrix Crack on Micromechanical Stress Field}

When the condition in Eq. (13) is met, matrix cracking will occur. With increasing load, the number of matrix cracks will increase. It is obvious that the multi-crack in the matrix will have a great influence on the micromechanical stress field and the development of microdamage in the composite.
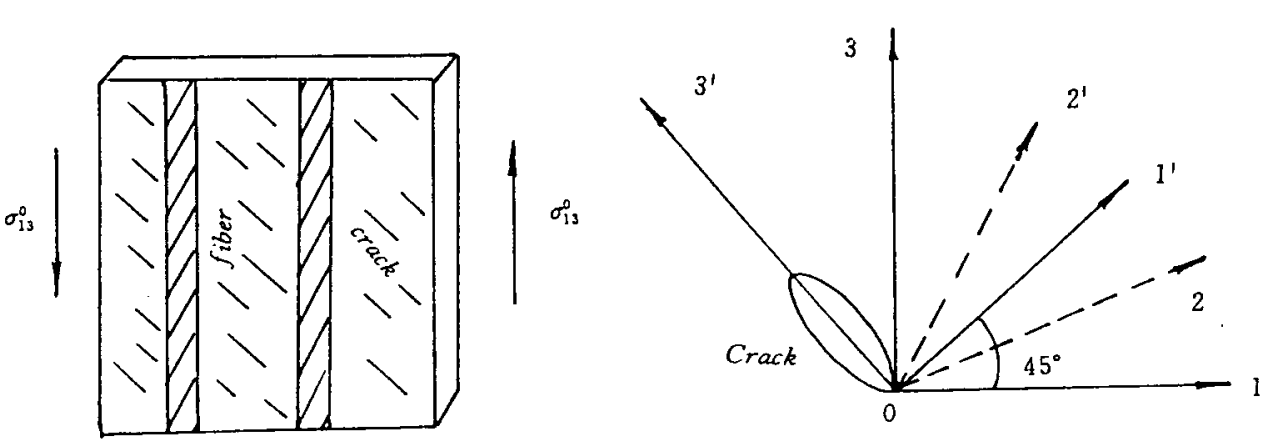

Fig. 20 Schematic Diagram for the Modeling of Mixed Inclusions: Fibera and Cracks

In order to analyze the influence, we simply assume all cracks in the matrix are penny shaped and aligned at $45^{\circ}$ to the shear direction. Hence the damaged unidirectional fiber reinforced composite can be treated as a body containing two kinds of inclusions, fibers and cracks as shown in Fig. 20. According to GEEM, there will be the following equivalent equations:

$$
\begin{aligned}
& \mathrm{C}_{\mathrm{ijk}}^{\mathrm{f}}\left(\varepsilon_{\mathrm{kl}}^{0}+\bar{\varepsilon}_{\mathrm{kl}}+\mathrm{S}_{\mathrm{klmn}}^{\mathrm{f}} \varepsilon_{\mathrm{mn}}^{*}\right)=\mathrm{C}_{\mathrm{ijk} \mathrm{d}}^{\mathrm{m}}\left(\varepsilon_{\mathrm{k} \mathrm{l}}^{0}+\bar{\varepsilon}_{\mathrm{kl}}+\mathrm{S}_{\mathrm{klmn}}^{\mathrm{f}} \varepsilon_{\mathrm{mn}}^{*}-\varepsilon_{\mathrm{kl}}^{*}\right) \\
& \mathrm{C}_{\mathrm{ijkl}}^{\mathrm{m}}\left(\mathrm{a}_{\mathrm{km}} \mathrm{a}_{\mathrm{ln}}\left(\varepsilon_{\mathrm{mn}}^{0}+\bar{\varepsilon}_{\mathrm{mn}}\right)+\mathrm{S}_{\mathrm{klpq}}^{\mathrm{c}} \varepsilon_{\mathrm{pq}}^{* *}-\varepsilon_{\mathrm{kl}}^{* *}\right)=0 \\
& C_{i j k l}^{m} \bar{\varepsilon}_{\mathrm{kl}}+\mathrm{V}_{\mathrm{f}} \mathrm{C}_{\mathrm{j} j \mathrm{kl}}^{\mathrm{m}}\left(S_{\mathrm{klmn}}^{\mathrm{f}} \varepsilon_{\mathrm{mn}}^{*}-\varepsilon_{\mathrm{kl}}^{*}\right)+\mathrm{V}_{\mathrm{c}} \mathrm{a}_{\mathrm{ik}}^{-1} \mathrm{a}_{\mathrm{jl}}^{-1} C_{\mathrm{klpq}}^{\mathrm{m}}\left(S_{\mathrm{pqrs}}^{\mathrm{c}} \varepsilon_{\mathrm{rs}}^{* *}-\varepsilon_{\mathrm{pq}}^{* *}\right)=0
\end{aligned}
$$

where $S_{i j k l}^{f}, \varepsilon_{i j}^{*}, V_{f} ; S_{i j k l}^{c}, \varepsilon_{i j}^{* *}, V_{c}$ are Eshelby tensor, equivalent eigenstrain, volume fractions of fibers and cracks, respectively. Besides, $\bar{\varepsilon}_{\mathrm{ij}}$ is the strain disturbance due to all inclusions and $a$ is the coordinate transformation tensor which is given by

$$
\mathbf{a}=\left(\begin{array}{ccc}
\cos \theta & 0 & \sin \theta \\
0 & 1 & 0 \\
-\sin \theta & 0 & \cos \theta
\end{array}\right), \quad \mathbf{a}^{-1}=\left(\begin{array}{ccc}
\cos \theta & 0 & -\sin \theta \\
0 & 1 & 0 \\
\sin \theta & 0 & \cos \theta
\end{array}\right)
$$

where $\theta=45^{\circ}$. For a longitudinal shear loading, following the procedure in the last section, we can obtain the following expressions from Eqs. (14), (15) and (16):

$$
\begin{gathered}
\varepsilon_{13}^{*}=2(1-K) B \varepsilon_{13}^{0} \\
\bar{\varepsilon}_{13}=\left((1+K) V_{c}+(1-K) V_{f}\right) B \varepsilon_{13}^{0}
\end{gathered}
$$




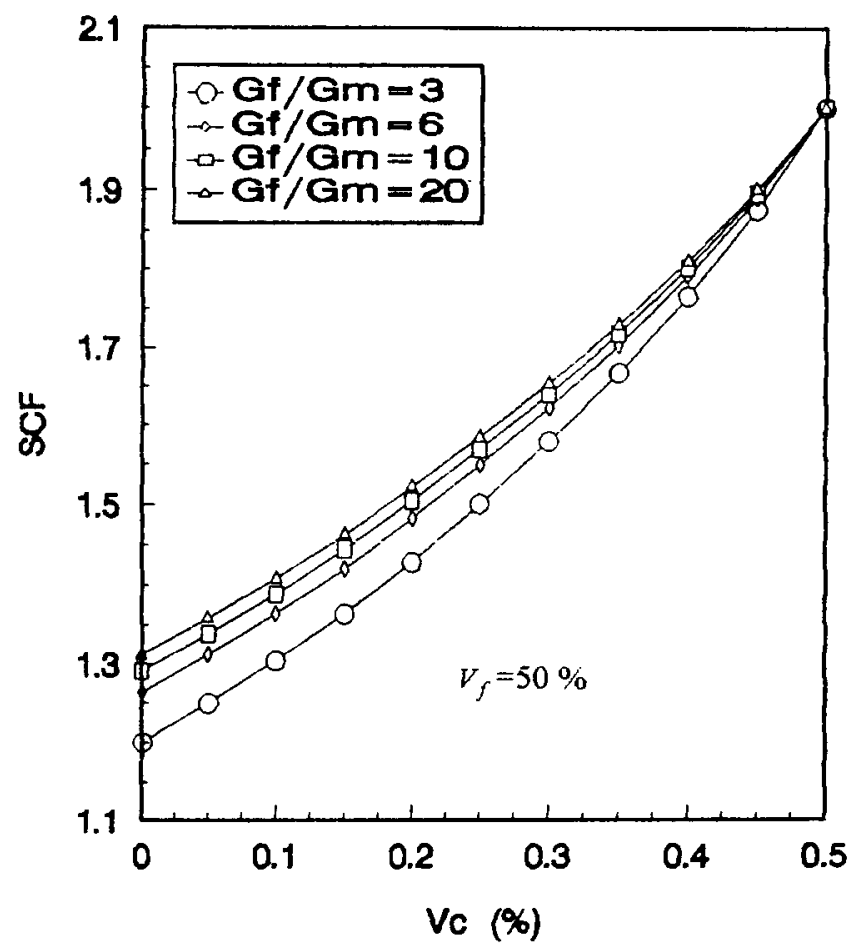

Fig. 21 Influence of Vc on Stress Concentration Factor in Fibers

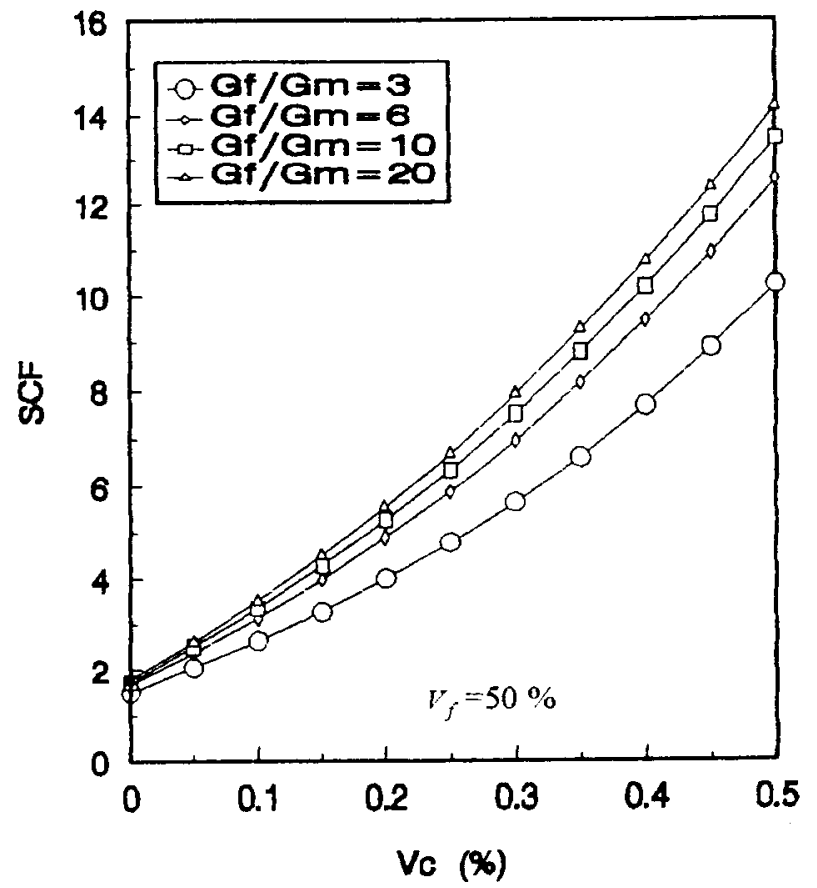

Fig. 22 Influence of Vc on Stress Concentration Factor at the Interface 
where $B=1 /\left(\left(2 K+(1-K)\left(1-V_{f}\right)\right)-(K+1) V_{c}\right)$ and $K=G_{f} / G_{m}$. It is obvious that if $V_{c}=0$, Eqs. (18) and (19) are the same as (7) and (8), respectively.

According to Eqs. (9) and (10), the SCF in the fibers and interfaces can be calculated, and the results are shown in Figs. 21 and 22. The results demonstrate that the crack volume fraction or density $V_{c}$ has a great effect on SCF in the fibers and the interfaces. Furthermore, the effect on the SCF at the interfaces is much higher than that in the matrix. This means shear debonding in the interfaces will occur under the high SCF and become a dominant damage mode, following the first stage of matrix cracking. Fig. 19 shows a large amount of interface debonding.

\subsection{Shear Failure Mechanism}

The nucleation and extension of the cracks in the matrix aggravates stress concentration in the interfaces greatly. This induces shear debonding along the interfaces. Apparently, the shear debonding will aggravates the stress concentration in the fibers further, then causes local fracture in the fibers and pulled-out. This leads to the macroscopic catastrophic shear failure of the composite. Therefore, the shear failure process of the unidirectional $C_{f} / A 356.0$ composite can be described as follows: shear induced tensile crack in the matrix(SITC) $\Rightarrow$ shear debonding at the interfaces $\Rightarrow$ local fracture in the fibers $\Rightarrow$ macroscopic shear failure in the composite. The failure process and the probable evolution process of the zigzag feature found on the failure surfaces of the composite (shown in Figs. 7-9) can be illustrated schematically in Fig. 23.

According to the aforementioned results, the shear failure of the unidirectional $C_{f} / A 356.0$ composite is dominantly controlled by SITC in the matrix and the shear debonding at the interfaces. These are also the primary shear failure mechanism for the composite under longitudinal shear loading. Therefore, in order to improve the capability of the unidirectional fiber reinforced metal matrix composites (FRMMC) to resist longitudinal shear failure, matrix with a high tensile strength and interfaces with a high shear strength are essential.

\section{CONCLUSIONS}

In the present study, the dynamic shear strength of both unidirectional $C_{\mathrm{f}} / \mathrm{A} 356.0$ composite and A356.0 aluminum alloy were measured with a split Hopkinson torsional bar apparatus. The results demonstrate that the shear strength of the composite is almost the same as that of the matrix. This indicates that the current carbon fiber orientation which aligns with the torsional loading axis does not improve the shear strength of the matrix effectively. The multi-stage shear process and the multiscale zigzags on the failure surfaces were observed. This provides an indication of the shear failure mechanisms in the unidirectional $C_{f} / A 356.0$ composite.

Micromechanical stress field in unidirectional fiber composites was also analyzed using the generalized Eshelby equivalent method (GEEM). The results indicated that the stress distribution in the composite are quite nonhomogeneous and there exist very high stress concentrations in the local regions of the matrix and the interfaces. By combining the analytical results and experimental observations, the shear failure mechanisms of the unidirectional $C_{f} / A 356.0$ composite can be described as follows: the initiation of damage is the shear induced tensile cracking (SITC) in the matrix. This aggravates stress concentrations at the interfaces and the fibers, hence causes the shear debonding along the interfaces and the local fracture in the fibers. At last, the macroscopic shear failure of the composite occurs. SITC in the matrix and shear debonding at the interfaces are the dominant damage modes which control shear failure. In order to improve the shear strength of the unidirectional fiber reinforced composites, matrix with a bigh tensile strength and interfaces with a high shear strength are essential. 


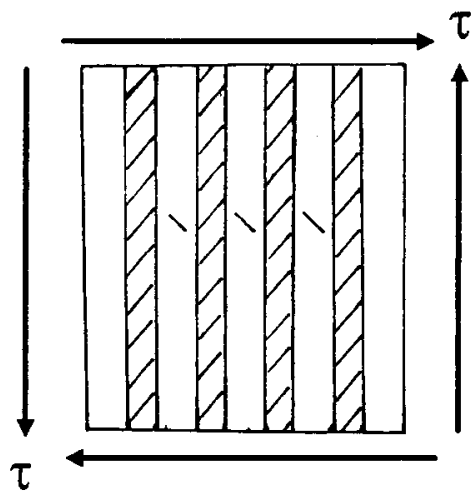

(a) Matrix Tensile Cracking

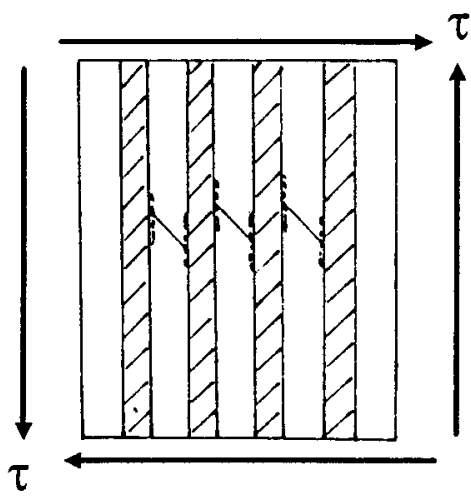

(c) Interface Shear Debonding

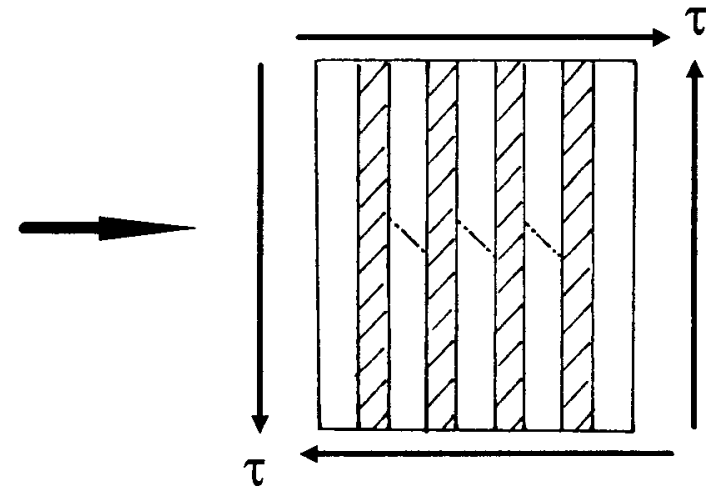

(b) Crack Extension

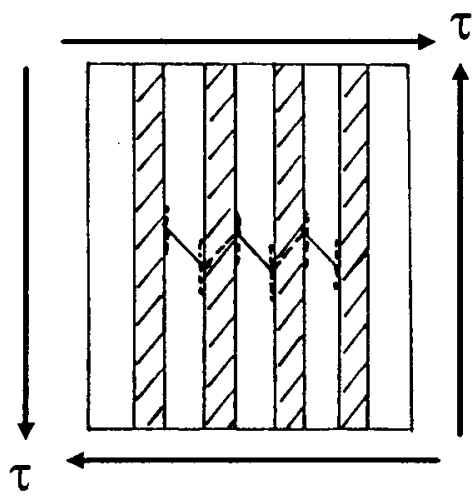

(d) Fiber Fracture

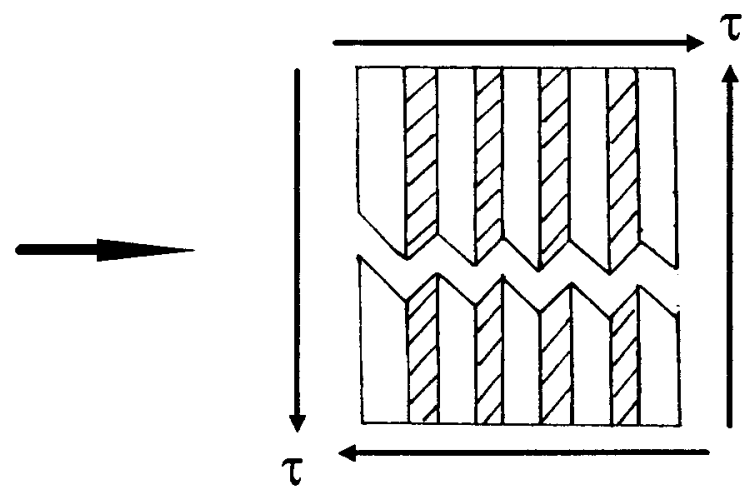

(e) Macroscopic Failure (Zigzag)

Fig. 23 Progressive Failure Mechanism of $\mathrm{C}_{\uparrow} / \mathrm{A} 356.0$ Composite under Torsional Shearing 


\section{REFERENCES}

[1] T. Parry, and J. Harding, in Plastic Behaviour of Anisotropic Solids, J.P. Boehler, ed., CNRS, Paris, 1988, pp. 271-288.

[2] C.Y. Chiem and Z.G. Liu, in Proc. European Mechanics Colloquium 214, W.A. Green \& M. Micunovic, ed., 1986, pp. 45-53.

[3] H. Leber and J.M. Lifshitz, Comp. Sci. Tech., 1996, Vol. 56, pp. 391-405.

[4] S.M. Werner and C.K. Dharan, J. Comp. Mater., 1986, Vol. 20, pp. 365-374.

[5] B. Bouette, C. Cazeneuve and C. Oytana, Comp. Sci. Tech., 1992, Vol. 45, pp. 313-321.

[6] J. Harding and Y.L. Li, Comp. Sci. Tech., 1992, Vol. 45, pp.161-171.

[7] L. Dond and J. Harding, Composites, 1994, Vol. 25, pp. 129-138.

[8] M.R. Piggott, Comp. Sci. Tech., 1995, Vol. 55, pp. 269-276.

[9] L.H. Dai, Shear Failure Mechanisms and Strength Design for Fiber Reinforced Metal Matrix Composites, Ph.D. Thesis, Inst. of Mech., Chinese Academy of Sciences, Beijing, 1996.

[10] S.W. Tsai, D.F. Adams and D.R. Doner, Effect of Constituent Material Properties on the Strength of Fiber Reinforced Composite Materials, AFML-TR-66-190, 1966.

[11] D.F. Adams, D.R. Doner and R.L. Thomas, Mechanical Behavior of Fiber Reinforced Composite Materials, AFML-TR-67-96, 1967.

[12] D.F. Adams, J. Comp. Mater., 1967, Vol. 1, pp. 4-17.

[13] J.G. Goree and A.B. Wilson Jr., J. App. Mech., 1967, Vol. 34, pp. 511-513.

[14] B. Budiansky and G.F. Carrier, J. App. Mech., 1984, Vol. 51, pp. 733-735.

[15] P.S. Steif, J. App. Mech., 1989, Vol. 56, pp. 719-721.

[16] J.D. Eshelby, Proc. Royal Soc., London, 1957, Vol. A241, pp. 376-396.

[17] T. Mori, and K. Tanaka, Acta Metall., 1973, Vol. 21, pp. 571-574.

[18] T. Mura, Micromechanics of Defects in Solids, Martinus, Nijhoff, Hague, 1987.

[19] M. Taya and T.W. Chou, Int. J. Solids. Struct., 1981, Vol. 17, pp. 553-563.

[20] Y. Takao, T.W. Chou, and M. Taya, J. App. Mech., 1982, Vol. 49, pp. 536-540.

[21] M. Taya and T. Mura, J. App. Mech., 1981, Vol. 48, pp. 361-367.

[22] Y. Benveniste, Mech. Mater., 1987, Vol, 6, pp. 147-157.

[23] T.C. Tszeng, Comp. Sci. Tech., 1994, Vol. 51, pp. 75-84.

[24] G.P. Tandon and G.J. Geng, J. App. Mech., 1988, Vol. 55, pp. 126-135.

[25] P.J. Withers, W.M. Stobbs and O.B. Pedersen, Acta Metall., 1989, Vol. 37, pp. 3061-3084.

[26] Y.L. Bai and B. Dodd, Adiabatic Shear Localization, Pergamon Press, New York, 1992. 
Impact Response and Dynamic Failure of Composites and Laminate Materials

10.4028/www.scientific.net/KEM.141-143

Material Response and Failure Mechanism of Unidirectional Metal Matrix Composites under Impulsive Shear Loading

10.4028/www.scientific.net/KEM.141-143.651

\section{DOI References}

[5] B. Bouette, C. Cazeneuve and C. Oytana, Comp. Sci. Tech., 1992, VoL 45, pp. 3 13-321. doi:10.1016/0266-3538(92)90046-6

[15] P.S. Steif, J. App. Mech., 1989, Vol. 56, pp. 719-721.

doi:10.1115/1.3176156

[16] J.D. Eshelby, Proc. Royal Soc., London, 1957, VoL A241, pp. 376-396.

doi:10.1098/rspa.1957.0133

[17] T. Mori, and K Tanaka, ActaMetall., 1973, VoL 21, pp. 571-574.

doi:10.1016/0001-6160(73)90064-3

[22] Y. Benveniste, Mech. Mater., 1987, Vol. 6, pp. 147-157.

doi:10.1016/0167-6636(87)90005-6

[23] T.C. Tszeng, Comp. Sci. Tech., 1994, Vol. 51, pp. 75-84.

doi:10.1016/0266-3538(94)90158-9

[25] P.J. Withers, W.M. Stobbs and O.B. Pedersen, ActaMetall., 1989, VoL 37, pp. 306 1-3084.

doi:10.1016/0001-6160(89)90341-6 